\title{
Jovens do Mercosul e suas ideias sobre presente, passado e futuro \\ Notas sobre a formação de sentido histórico
}

\author{
Cristiani Bereta da Silva \\ Luciana Rossato
}

\section{SciELO Books / SciELO Livros / SciELO Libros}

SILVA, C.B., and ROSSATO, L. Jovens do Mercosul e suas ideias sobre presente, passado e futuro: Notas sobre a formação de sentido histórico. In: CERRI, L.F., ed. Os jovens e a História: Brasil e América do Sul [online]. Ponta Grossa: Editora UEPG, 2018, pp. 15-39. ISBN: 978-85-7798-248-6. https://doi.org/10.7476/9788577982486.0002.

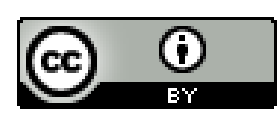

All the contents of this work, except where otherwise noted, is licensed under a Creative Commons Attribution $\underline{4.0 \text { International license. }}$

Todo o conteúdo deste trabalho, exceto quando houver ressalva, é publicado sob a licença $\underline{\text { Creative Commons }}$ Atribição 4.0. 


\section{JOVENS DO MERCOSUL E SUAS IDEIAS SOBRE PRESENTE, PASSADO E FUTURO: NOTAS SOBRE A FORMAÇÃO DE SENTIDO HISTÓRICO}

Cristiani Bereta da Silva

Luciana Rossato

\section{INTRODUÇÃO}

Analisamos, neste capítulo, questões sobre a formação de sentido histórico por meio das respostas dadas por jovens brasileiros, uruguaios, argentinos, paraguaios e chilenos, com idade entre 15 e 16 anos, às perguntas relacionadas ao tempo e à História. Mesmo com idades tão próximas, os jovens, aos quais nos referimos, são bastante diferentes, uma vez que são de países, culturas, escolas diversas. Não obstante a isto, observa-se que possuem uma característica comum: são todos estudantes. Para este capítulo, privilegiamos as respostas dadas por estes estudantes a 9 questões (PROYECTO ZORZAL, [s.d.]) específicas, entre as 43 questões do questionário aplicado na pesquisa. Recortamos essas perguntas, pois nosso interesse é identificar como a noção de futuro aparece nas respostas dos estudantes em suas relações com o passado e com o presente e, a partir de então, problematizar questões sobre a consciência histórica e a formação de sentido histórico desses jovens.

O universo abordado trata de uma amostra que não é probabilística, nem estatisticamente representativa dos jovens do Mercosul. Isto significa que, muito embora a pesquisa lide com quase 4 mil respostas, as análises não podem servir a generalizações. Contudo, justamente porque lidam com um universo tão amplo, podem contribuir para estudos e reflexões sobre os jovens e suas ideias históricas; no limite, também podem fornecer pistas sobre a formação de sentido histórico. O trabalho com dados quantitativos, no campo da História, ainda causa desconfianças e estranhamentos entre os pares, que chamam a atenção para os limites do alcance de algumas análises construídas por meio de dados matemáticos. Defendemos, 
contudo, que o trabalho com dados probabilísticos tem potencialidades e desafios, tanto quanto outros métodos de pesquisa, que se utilizam de outras linguagens que não a matemática. Abordagens de amplo espectro - como a da pesquisa citada - podem contribuir para uma aproximação da realidade observada, conquanto que saibamos que nunca serão suficientes para a compreensão dessa mesma realidade. Mas esses limites e desafios também estão presentes em outras abordagens consideradas qualitativas, como bem pontuam Maria Cecília Minayo e Odécio Sanches (1993), sobre o tratamento quantitativo e qualitativo nas pesquisas.

Sobre esse ponto, também acompanhamos Luis Fernando Cerri (2014), em sua defesa da possibilidade de captar evidências sobre consciência histórica em pesquisas que lidam com dados estatísticos. Seu argumento assenta-se no seguinte pressuposto: se a consciência histórica se expressa em narrativas (RÜSEN, 2007, 2009; 2014), é plausível supor que, ao responder uma questão - mesmo que fechada, de um questionário - o sujeito busque referências de narrativas conhecidas para expressar sua opinião. Para Cerri (2014, p. 183), quando o sujeito pesquisado decide diante de uma história e escolhe uma das alternativas apresentadas, ele "permite que o observador entreveja o exato momento em que a orientação temporal da consciência histórica atua, estabelecendo o elo dinâmico entre o passado que experienciou e o futuro que projeta, na ação que escolhe". Se concordamos que, mesmo se diferenciando em aspectos importantes, a "consciência histórica é uma forma específica de memória histórica” (RÜSEN, 2009, p. 168), e se assumimos o pressuposto que ela está "estreitamente ligada com a memoração" (RÜSEN, 2014, p. 99); ou seja, com o ato de lembrar, é válido supor que é na sua experiência de vida, na interpretação de narrativas, na percepção e orientação temporal, bem como de pertencer a um coletivo, que o sujeito busca elementos para argumentar ou atribuir resposta a uma pergunta feita. Nesta clave, consciência histórica é constituição de sentido sobre a experiência do tempo, e é inseparável da formação histórica. Formação tomada, aqui, como competências acionadas pelo sujeito para interpretar o mundo em que vive e a si próprio, articulando "o máximo de orientação do agir com o máximo de autoconhecimento, possibilitando 
assim o máximo de auto-realização [sic] ou de reforço identitário" (RÜSEN, 2007, p. 95).

A discussão sobre a consciência histórica e a formação de sentido histórico inclui, necessariamente, pensar tanto "nos modos de representação que dão ao passado a forma distintiva de história" (RÜSEN, 2009, p. 168), como no inter-relacionamento do passado, presente e futuro contidos nessa mesma representação. A relação temporal é sempre mediada, quando se trata de consciência histórica, pois esta significa a compreensão da experiência do tempo para a interpretação do presente e a orientação para o futuro.

A abordagem sobre o tempo é irrenunciável na discussão proposta, e implica um diálogo não apenas com a didática da História, também com a filosofia da História. A didática da História, tomada com base nos estudos de Rüsen (2007) e Bergmann (1990), constitui parte indissociável da teoria da História. A didática da História estuda não apenas a realidade escolar, também os processos e funções da consciência histórica elaborados pelos sujeitos a partir de orientações formais e escolares, bem como informais e extraescolares. A teoria da História e a didática convergiriam quanto às operações e aos processos existenciais da consciência histórica, sendo elaboradas, porém, de maneiras distintas. Para Klaus Bergmann (1990, p. 30-32), as pesquisas orientadas desse campo devem incluir, entre os objetos de suas investigações, as recepções extraescolares ou extracientíficas de história, que atravessam o cotidiano e constituem o vivido dos indivíduos das mais diferentes formas. Entre esses objetos, que possuem seus efeitos para a formação histórica, estão a televisão, o cinema, a imprensa, as conversas cotidianas, os museus, a literatura histórica, as propagandas históricas, as representações científicas e populares sobre o passado, os livros didáticos, os monumentos, os edifícios e nomes de ruas que lembram eventos históricos, entre outros.

A filosofia da História fornece princípios importantes para a compreensão do tempo na configuração da existência. Para Paul Ricoeur (2007), a temporalidade constitui a característica principal do ser que somos, assinalando distinções no modo de ser que somos a cada vez, nas maneiras de surgir nos cenários do mundo, de existir e habitar esses mundos de 
diferentes formas. A partir do diálogo estabelecido com Heidegger em Ser e Tempo, Ricoeur (2007) discute sobre os três modos de temporalização e as perspectivas inéditas que essa forma de ordenar a experiência temporal abriria para o confronto entre a filosofia e a epistemologia da História. $\mathrm{Na}$ tripartição proposta por Heidegger, temporalidade (orientação para o futuro), historicidade (o intervalo que se estende ou que se estica entre um acontecimento e outro), intratemporalidade (evidenciaria a preocupação com o presente), Ricoeur (2007) vê a preocupação com o futuro como fundamental, mesmo que não possa prescindir da correlação dos três níveis. O futuro, nesse processo, teria função preponderante, posto que seria a relação com o futuro que induziria a sequência das outras determinações temporais da experiência histórica. Encetando diálogo também com Koselleck, sobre o "horizonte de expectativa e espaço de experiência", Ricoeur (2007, p. 374) destaca que a noção "de estar em dívida" seria o "conceito ponte", o elo entre futuridade e preteridade, pois "a resolução antecipadora só pode ser um assumir a dívida que marca nossa dependência do passado em termos de herança." Se a ideia de futuro é marca indelével na configuração do sentido da existência humana, não seria diferente na configuração da consciência histórica, que "sempre tem o futuro como ponto de referência” (RÜSEN, 2014, p. 97), mesmo que sua função orientadora ocorra a partir da experiência do passado. Isto porque ela está sempre em processo de imbricamento do "horizonte de experiência, no qual o passado está presente de diferentes modos, e o horizonte de expectativa, no qual o agir (e o sofrer) se projeta(m) de modo finalista" (RÜSEN, 2014, p. 97). A orientação para o passado da consciência histórica estaria constantemente provendo esse direcionamento com expectativas normativamente carregadas, ou seja, com orientação para o futuro. A expectativa da discussão que propomos é justamente pensar o futuro acionado nas respostas desses jovens e, assim, compreender a própria relação que essa geração estabelece com as temporalidades.

\section{JOVENS: ALGUMAS QUESTÕES}

Quem são os jovens que responderam aos questionários? Quais as características desse grupo de indivíduos, que são identificados como jovens 
e/ou adolescentes ${ }^{1}$ ? Este grupo é visto de modo homogêneo, se considerado a partir do recorte de idade, mas é marcado por heterogeneidade, se for analisado a partir da composição dos indivíduos, devido as suas características socioeconômicas, de gênero e étnico-raciais. Pierre Bourdieu (1983, p. 2) escreve que a

idade é um dado biológico socialmente manipulado e manipulável; e que o fato de falar dos jovens como se fossem uma unidade social, um grupo constituído, dotado de interesses comuns, e relacionar estes interesses a uma idade definida biologicamente já constitui uma manipulação evidente.

Os estudos sobre juventude salientam que este conceito é marcado pela imprecisão e ambiguidade. Apesar de um dos ordenadores sociais ser a idade (junto com o sexo), este grupo não pode ser definido somente por este aspecto. Infância, juventude e velhice são recortes imprecisos, que variam conforme o contexto histórico, e são marcados por grandes diferenças, conforme a classe, o gênero, a religião e a etnia. Juventude é um conceito que pode ser definido como uma etapa da vida (de preparação, no qual, aos jovens, é permitida uma indefinição não permitida em outros períodos etários), como um período de moratória e, também, por seu valor simbólico ou como um produto (MARGULIS; URRESTI, 1996).

Os jovens que estamos analisando constituem um grupo que, além de terem a mesma idade, têm sua identidade marcada por outra característica comum: todos são estudantes, uma vez que a pesquisa foi realizada em escolas no Brasil e em outros países do Mercosul. No entanto, apesar destes dois aspectos, este grupo é heterogêneo, pois a pesquisa foi realizada

\footnotetext{
${ }^{1}$ A juventude e a adolescência, apesar de muitas vezes tratadas como sinônimos, diferenciam-se de acordo com definições de faixa etária, representação social e áreas de conhecimento. O termo adolescente foi definido a partir dos estudos sobre as transformações biológicas e psicológicas pelas quais passam os indivíduos entre os 12 e 18 anos de idade. Este termo, forjado pela Biologia e Psicologia, acabou se difundindo entre os educadores. Já o termo jovens/juventudes é analisado a partir do olhar sociológico e histórico, e tem como foco as características socioeconômicas e culturais. Existem variados recortes etários para estabelecer uma faixa da população como jovem. A OMS e a UNESCO adotam o recorte de 15 a 24 anos. Tal recorte foi convencionado em 1964, na Conferência de Grenoble, baseando-se em dois limites: a) idade mínima para adentrar no mercado de trabalho; b) expectativa para a conclusão da escolarização formal. Porém, mais recentemente, alguns países, incluindo o Brasil, através da SNJ e do CONJUV, adotaram um recorte mais extenso: 15 a 29 anos (Lei 12.852/2013, BRASIL, 2013). Já a adolescência é reconhecida, tanto por órgãos internacionais como pelo governo brasileiro, como perfazendo o intervalo entre os 12 e os 18 anos. A lei no 8.069, de 13 de julho de 1990 (BRASIL, 1990), criou o ECA, legislação para menores de idade em vigor no Brasil.
} 
em diferentes escolas: públicas e privadas, de municípios grandes, médios e pequenos, centrais e de periferia, laicas e religiosas, além de ter sido realizada em 5 países diferentes. Os estudantes/as pesquisados são jovens que vivenciam esta fase de sua vida de diferentes formas, bem como vivenciam o processo de escolarização de modos diversos. Para Juarez Dayrell (2007), os jovens que chegam às escolas públicas, atualmente, são muito distintos dos jovens de gerações anteriores, uma vez que existem diferentes formas de vivenciar a condição juvenil. Os jovens nascidos na década de 1990 em diante estão inseridos em uma sociedade que ressignifica constantemente sua relação com o tempo e o espaço, devido às transformações decorrentes da difusão do uso da internet.

Outro aspecto a ser considerado é que uma grande parcela dos jovens brasileiros ${ }^{2}$ não usufrui da moratória em relação ao trabalho, o que é muito comum entre os jovens europeus. No entanto, a inserção dos jovens no mercado de trabalho não é fácil, em decorrência das relações precárias de trabalho e dos altos índices de desemprego que afetam, principalmente, aqueles pertencentes às classes populares. Muitos jovens precisam conciliar o estudo e o trabalho, o que afeta sua trajetória educacional, uma vez que a possibilidade de viver a condição juvenil passa pela necessidade de trabalhar para ter acesso ao lazer e ao consumo (DAYRELL, 2007).

O processo de escolarização, no Brasil, tem passado por muitas transformações nas últimas décadas. No decorrer da década de 1990, ocorreu a expansão das escolas em diferentes níveis de ensino, o que significou uma mudança no perfil dos estudantes, que se tornou mais heterogêneo, pois crianças e jovens das classes populares, que antes não tinham acesso (ou eram expulsos das escolas), passaram a ser inseridos no ambiente escolar. Esta inserção dos jovens no processo de escolarização ainda não foi concluída no Brasil, apesar da obrigatoriedade do Ensino Médio, instituído através da lei 12.061/2009 (BRASIL, 2009). Esta mudança no perfil dos estudantes significou novas demandas e novos desafios para os que estão envolvidos nos processos educacionais nas escolas.

\footnotetext{
${ }^{2}$ As relações que estabelecemos com o contexto educacional serão feitas a partir dos dados no Brasil, uma vez que não conhecemos em profundidade a realidade dos jovens e da Educação nos outros países da pesquisa.
} 
Figura 1 - Como são os jovens de nosso país? Marque apenas uma alternativa, a que você considerar mais importante (em porcentagens)

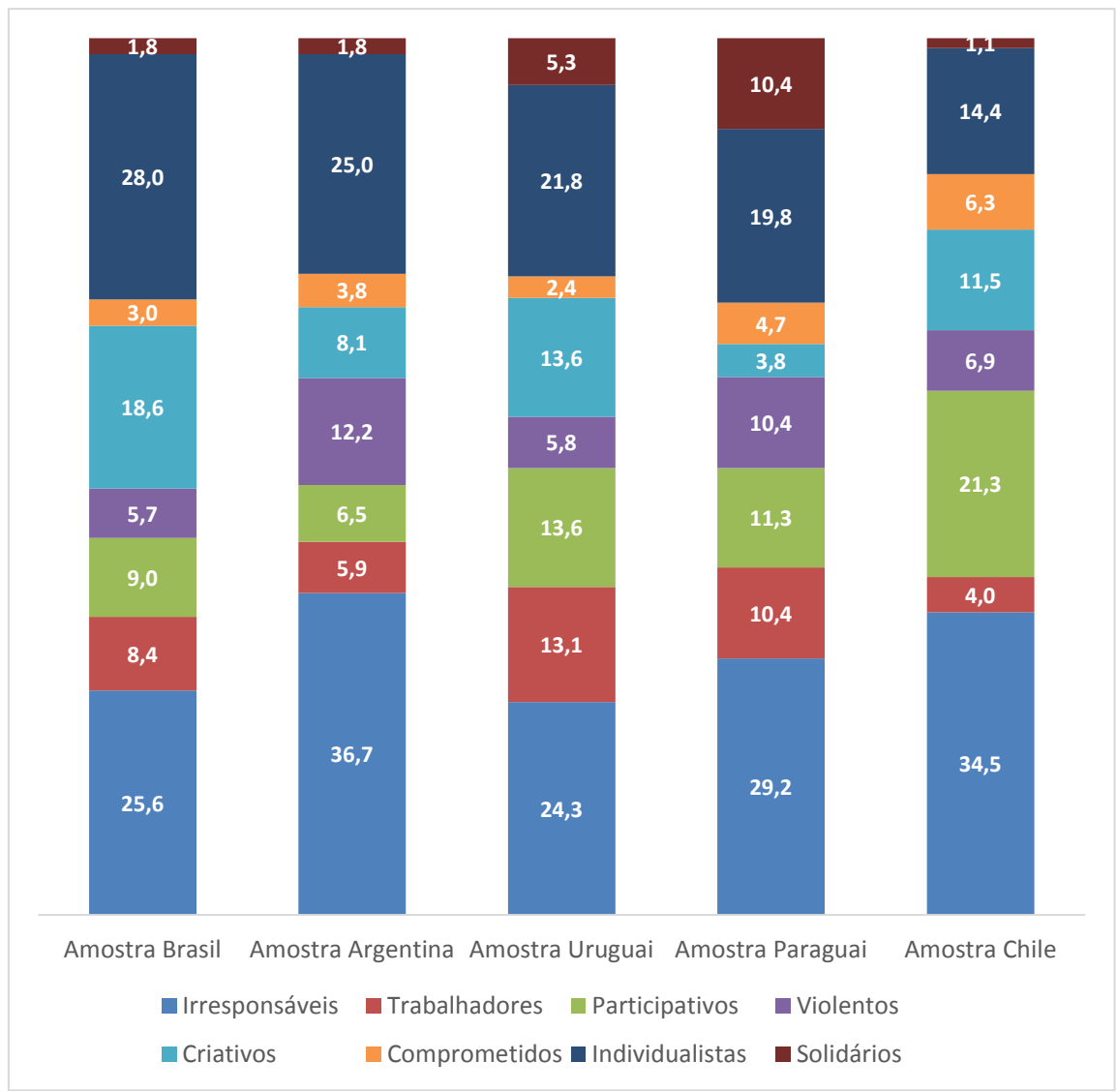

Fonte: Dados do projeto Jovens e a História. Questão ํo38 (2013). Disponível em: <http://proyectozorzal.org>. Acesso em: 22 jul. 2017.

A partir de duas questões respondidas pelos estudantes, a questão $\mathrm{n}^{\circ} 38$ - Como são os jovens de nosso país? Marque apenas uma alternativa, a que você considerar mais importante ${ }^{3}$ - e a questão $\mathrm{n}^{0} 42$ - Marque apenas uma alternativa, a que você considerar mais importante: em sua opinião, a juventude deve: ${ }^{4}$ - é possível entender como os jovens se auto identificam e qual deve ser sua atuação na sociedade atual nos diferentes países pesquisados. Em relação a auto representação dos jovens, constata-se que estes se identificam

\footnotetext{
${ }^{3}$ Para o espanhol, a pergunta foi vertida da seguinte forma: ¿Cómo es la gente joven de nuestro país? ${ }^{4}$ Para o espanhol, a pergunta foi vertida da seguinte forma: ¿En tu opinión, la juventud debe...?
} 
de modo negativo. Irresponsáveis e individualistas foram os itens mais votados em todos os países analisados. Criativos, violentos e participativos alternam-se em $3^{\circ}$ lugar, em diferentes países. No Brasil, a característica que obteve maior percentual foi o individualismo, com $28 \%$; seguido de irresponsáveis, com $25,6 \%$; e de criativos, com $18,6 \%$. Já entre os argentinos, chama a atenção o alto índice dos que afirmam que os jovens são irresponsáveis, o maior entre os países, com $36,7 \%$. Se somarmos este número com os $12,2 \%$ dados para violentos, e os $25 \%$ para individualistas, teremos um índice de 73,9\% de entrevistados que definem os jovens por seus defeitos. Os dados dos outros países não são tão dramáticos como, por exemplo, no Brasil, onde 59,3\% dos jovens se identificam negativamente, mas chama a atenção o fato de, em todos os países os entrevistados, terem se auto identificado de forma negativa.

Esta representação negativa da juventude, pelos próprios estudantes pesquisados e que são jovens, pode ser entendida de melhor forma se refletirmos à luz das representações sobre os jovens e a juventude que se difunde nos meios de comunicação. Estas representações estão assinaladas em pesquisas desenvolvidas, principalmente pelos sociólogos, no decorrer do século XX.

A juventude - como categoria social - surgiu com força no pós-guerra nos EUA, e muda a forma como este período da vida passa a ser percebido, tanto pelos adultos como pelos próprios jovens ${ }^{5}$. Na década de 1950, a juventude passou a ser vista como um período difícil, de questionamento e contestação. Isto é bastante veiculado por meio do cinema como, por exemplo, no filme Juventude Transviada, de 1955. Naquele momento, a rebeldia passou a ser vista como um estado pelo qual todos os jovens passariam, e não mais só os que integrariam as chamadas classes perigosas. A rebeldia deixou de ser demonizada, como restrita às classes perigosas, e passou a ser vista como normal, até mesmo como fonte de inovação e revigoramento social, desde que devidamente controlada através da recondução, após um tempo, destes rebeldes, aos padrões de normalidade estabelecidos socialmente.

\footnotetext{
${ }^{5}$ Sobre isto, ver os capítulos 29 e 30 de SAVAGE, Jon. A criação da Juventude: como o conceito de teenage revolucionou o século XX. Rio de Janeiro: Rocco, 2009.
} 
Já na década de 1960 e de 1970, os movimentos juvenis proliferaram e se ampliaram. Os jovens que participavam destes movimentos questionavam as organizações políticas, sociais, culturais e a moralidade das sociedades ocidentais. Eles se recusavam a se enquadrar. No Brasil, uma parcela dos jovens se envolveu nos movimentos contrários à ditadura civil-militar, e participou de movimentos culturais que questionavam os padrões culturais e morais. Segundo Helena Abramo (2007, p. 82), os "jovens apareciam como uma fonte de energia utópica do que propriamente pessoas capazes de levar a cabo efetivamente tal transformação". Salienta-se que esta imagem positiva dos jovens, dos anos 60 e 70 (idealistas, rebeldes, inovadores, utópicos), vai se construir, posteriormente, na década de 1980, quando os jovens serão vistos como apáticos, desinteressados e desmobilizados. Um exemplo desta representação sobre os jovens brasileiros dos anos 80 pode ser encontrado na música Terra de Gigantes, interpretada pela banda Engenheiros do Hawaii e composta por Humberto Gessinger, em 1987.

Já na década de 1990, os jovens passaram a se envolver com ações individuais e coletivas, ações fragmentadas, violentas, de desvio e desregramento. Os jovens passaram a ser vistos como vítimas, bem como promotores da dissolução social. A proclamação do ano de 1985, como Ano Mundial da Juventude pela ONU, e a promulgação do Estatuto da Criança e do Adolescente em 1990 (BRASIL, 1990) fez com que a questão da juventude se tornasse um tema de discussão pelo estado brasileiro, que iniciou uma série de políticas públicas voltadas para esta parcela da população brasileira que, anteriormente, somente era atendida a partir de sua inserção no espaço escolar (ABRAMO, 2007, KEHL, 2004, ABRAMO, 2008, PERALVA, 2007, DAYRELL 2007).

A imagem dos jovens na atualidade, como irresponsáveis, individualistas, desinteressados e apáticos é recorrente, também entre os/as professores/as, que reproduzem, de certo modo, uma representação repetida reiteradamente pelos meios de comunicação, principalmente a partir da década de 1990, quando a juventude passou a ser mais do que uma fase da vida, mas um signo possível de ser alcançado através do consumo. Um signo que passou a ser considerado o padrão cultural a ser atingido por 
todos, e que é marcado pelo individualismo, pelo efêmero, pelas relações descompromissadas, pela despreocupação com o futuro.

Enquanto a questão $\mathrm{n}^{0} 38$ queria saber como era, na opinião dos entrevistados, a juventude em seu país, a questão $\mathrm{n}^{0} 42$ - Em sua opinião, a juventude deve... - procura mapear qual a opinião dos estudantes sobre como deve ser a juventude e quais devem ser suas preocupações. As opções de respostas contemplam o compromisso com o social (lutar por suas ideias/ ideais e assumir responsabilidades trabalhando), a realização pessoal (formarse para o futuro e definir objetivos de vida para si) e uma opção hedonista (divertir-se e curtir a vida).

Figura 2 - Em sua opinião a juventude deve... (em porcentagens)

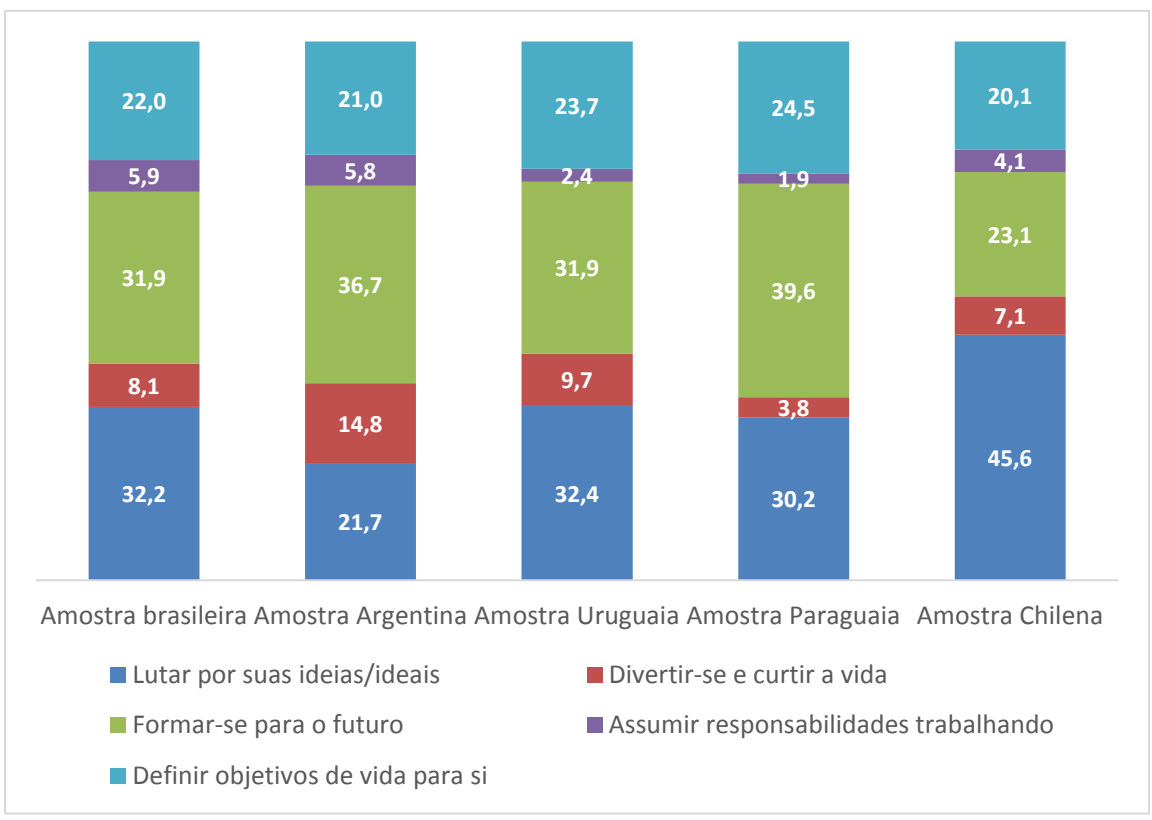

Fonte: Dados do projeto Jovens e a História. Questão n 42 (2013). Disponível em: <http://proyectozorzal.org>. Acesso em: 22 jul. 2017.

As respostas, no geral, mostram que os estudantes se dividiram entre as demandas pessoais, de se preparar para o futuro, e uma preocupação com o coletivo, de lutar por suas ideias/ideais. No entanto, aos analisarmos as respostas por países, identifica-se que, entre os brasileiros e uruguaios, estes dois itens obtiveram resultados muito próximos, o que mostra que os 
estudantes estão divididos entre as preocupações com o coletivo e com as demandas individuais. Já entre os argentinos e os paraguaios, a preocupação com o futuro individual foi predominante. O que chama a atenção é o resultado entre os chilenos, no qual $45 \%$ dos respondentes assinalaram que a luta por suas ideias/ideais é o aspecto que deve ser a prioridade da juventude. O que se salienta é a diferença entre a juventude que se apresenta nessas respostas e a imagem extremamente negativa sobre os jovens, indicada nos resultados da questão $\mathrm{n}^{\circ} 38$. Os resultados mostram que, o que se espera da juventude, é uma postura de responsabilidade com o futuro individual e mesmo com o coletivo, com uma baixa porcentagem (em torno de 5\%) dos entrevistados assinalando o item $42 \mathrm{~b}$, divertir-se e passar bem. Isto contradiz a imagem negativa sobre os jovens, que aparece nos resultados gerais da questão $\mathrm{n}^{\circ} 38$, quando a maioria assinalou, como característica predominante da juventude, a irresponsabilidade. Ao comparar as respostas das questões $n^{\circ} 38$ e $n^{\circ} 42$, pode-se inferir que os jovens incorporaram o discurso que circula, principalmente na mídia e entre os professores, de que eles são os responsáveis pelo futuro, mas que, no presente, eles são irresponsáveis. Os jovens são alvo de confiança (no futuro) por parte dos adultos, mas são alvo de desconfiança e medo (no presente). Este discurso maniqueísta é tão enraizado no senso comum que, mesmo os jovens, alvo deles, o reproduzem.

\section{OS JOVENS E O TEMPO PRESENTE, PASSADO E FUTURO}

Quando a um jovem é perguntado sobre a história ou sobre o passado de seu país, a orientação para o futuro é tão preponderante quando perguntado sobre o futuro, observando-se, claro, a relação mediada e inter-relacionada entre passado, futuro e presente. Como já informado, para este capítulo foram recortadas 9 questões específicas, com o objetivo de analisar a consciência histórica e a formação de sentido histórico entre os jovens estudantes. A pergunta $\mathrm{n}^{\circ} 2$ do questionário aplicado aos estudantes queria saber - dentre três alternativas apresentadas: a) Conhecer o passado; b) Compreender o presente; c) Buscar orientação para o futuro - qual seria a mais importante como objetivo ao se estudar a História. Os 
estudantes precisaram escolher, para cada uma delas, as seguintes variações: muito pouca; pouca; alguma; importante, muito importante, como se pode observar na tabela abaixo.

Tabela 1 - Em sua opinião, qual a importância de cada um dos objetivos ao se estudar a História: (em porcentagens)

\begin{tabular}{|c|c|c|c|c|}
\hline & & $\begin{array}{l}\text { Conhecer } \\
\text { o passado }\end{array}$ & $\begin{array}{l}\text { Compreender } \\
\text { o presente }\end{array}$ & $\begin{array}{l}\text { Buscar } \\
\text { orientação } \\
\text { para o futuro }\end{array}$ \\
\hline \multirow{5}{*}{$\begin{array}{l}\text { Amostra } \\
\text { Brasil }\end{array}$} & Muito pouca importância & 5,6 & 5,0 & 6,1 \\
\hline & Pouca importância & 3,0 & 5,2 & 8,5 \\
\hline & Alguma importância & 11,8 & 15,1 & 17,6 \\
\hline & Importante & 46,1 & 41,0 & 33,8 \\
\hline & Muito importante & 33,5 & 33,8 & 33,9 \\
\hline \multirow{5}{*}{$\begin{array}{l}\text { Amostra } \\
\text { Argentina }\end{array}$} & Muito pouca importância & 2,7 & 1,6 & 6,6 \\
\hline & Pouca importância & 6,2 & 7,3 & 15,9 \\
\hline & Alguma importância & 17,6 & 19,1 & 19,0 \\
\hline & Importante & 48,4 & 41,9 & 26,7 \\
\hline & Muito importante & 25,0 & 30,2 & 31,8 \\
\hline \multirow{5}{*}{$\begin{array}{l}\text { Amostra } \\
\text { Uruguai }\end{array}$} & Muito pouca importância & 1,4 & 0,9 & 6,0 \\
\hline & Pouca importância & 0,9 & 5,0 & 14,3 \\
\hline & Alguma importância & 16,5 & 15,8 & 26,3 \\
\hline & Importante & 49,5 & 39,6 & 30,4 \\
\hline & Muito importante & 31,7 & 38,7 & 23,0 \\
\hline \multirow{5}{*}{$\begin{array}{l}\text { Amostra } \\
\text { Paraguai }\end{array}$} & Muito pouca importância & 4,2 & 1,7 & 2,6 \\
\hline & Pouca importância & 3,4 & 4,3 & 3,4 \\
\hline & Alguma importância & 8,5 & 22,6 & 17,1 \\
\hline & Importante & 51,7 & 41,7 & 26,5 \\
\hline & Muito importante & 32,2 & 29,6 & 50,4 \\
\hline \multirow{5}{*}{$\begin{array}{l}\text { Amostra } \\
\text { Chile }\end{array}$} & Muito pouca importância & 1,9 & 1,2 & 1,8 \\
\hline & Pouca importância & 1,9 & 1,8 & 7,1 \\
\hline & Alguma importância & 6,3 & 13,5 & 17,8 \\
\hline & Importante & 43,4 & 32,2 & 36,1 \\
\hline & Muito importante & 46,5 & 51,5 & 37,3 \\
\hline
\end{tabular}

Fonte: Dados do projeto Jovens e a História. Questão no 2 (2013). Elaboração das autoras. 
Como era previsível, a maior parte das respostas dos jovens reportouse à importância do passado. Quando se considera o conjunto de todas as amostras, $78 \%$ deles responderam que o estudo da História é importante ou muito importante para conhecer o passado. O que não era tão previsível foi $75 \%$ dos jovens consideraram que a História é importante ou muito importante, também, para compreender o presente, e que $65 \%$ opinaram que é importante para buscar orientação para o futuro. Nos diferentes países, a tendência se assemelha, ainda que com variações de intensidade. Neste caso, para além de ponderar que os jovens opinaram considerando a resposta que eles achavam que os pesquisadores esperavam, também se pode cogitar que essas perspectivas (presente e futuro) têm sido enfatizadas nas aulas de História desses países.

No Brasil, apesar dos livros didáticos ${ }^{6}$ trazerem os conteúdos históricos majoritariamente organizados a partir da lógica cronológica linear (MIRANDA; LUCA, 2004), a presença de outras concepções de História, como a história-problema da Escola dos Annales, tem ampliado a concepção sobre o papel da História escolar. Este questionamento ocorreu a partir do retorno da História como disciplina autônoma nos anos de 1980, com a reabertura política, e que vai estabelecer, como função do ensino de História, a formação para a cidadania, o que se fortalece com a publicação dos Parâmetros Curriculares Nacionais (PCN) em 1996, que definiu, como fundamental para a aprendizagem histórica, a discussão de conceitos como tempo, fato histórico, sujeito histórico, e o estabelecimento de temas transversais, entre os quais, cidadania.

Além disso, a aprovação, em 2003, da lei 10.639 (que estabeleceu a obrigatoriedade do ensino de História e cultura africanas e afro-brasileiras e uma educação das relações étnico-raciais na escola, BRASIL, 2003), modificada pela Lei 11.645/2008 (que incluiu a obrigatoriedade do ensino de História indígena, BRASIL, 2008), trouxe para o debate questões como a pluralidade cultural, as discussões sobre as relações étnico-raciais e o questionamento da história eurocêntrica. Na Argentina e no Chile, a discussão pública sobre o período dos governos militares é muito distinta do

\footnotetext{
${ }^{6}$ A maioria dos estudantes brasileiros tem acesso a eles através do Programa Nacional do Livro Didático (PNLD), do Ministério da Educação (MEC).
} 
que ocorre no Brasil. No caso argentino, os debates públicos, denúncias e questionamentos em relação ao governo militar começaram após a derrota na Guerra das Malvinas, em 1982. No campo educacional, dois eventos da última ditadura militar tornaram-se efemérides escolares, momentos para refletir sobre um passado doloroso: o 24 de março (aniversário do golpe) e o 16 de setembro (aniversário da Noite dos Lápis) ${ }^{7}$. Além disso, na década de 1980 começaram a ser julgados os abusos cometidos pelo Estado argentino através dos órgãos de repressão, o que fez com que o tema dos desaparecidos políticos fosse amplamente divulgado pela imprensa (LORENZ, 2007).

As questões 19 e 20 incidem diretamente sobre estas perspectivas, buscando indícios mais concretos sobre o ensino de História nas escolas e a formação de sentido histórico. A questão de $\mathrm{n}^{\circ} 19$ colocava em perspectiva o passado em relação ao presente - Que influência você acha que tiveram os seguintes fatores na mudança na vida das pessoas desde 1970 até hoje? ${ }^{8} \mathrm{E}$ outra colocava a perspectiva do futuro em relação ao presente, $\mathrm{n}^{\circ} 20$ - Que influência você acha que terão os seguintes fatores na mudança da vida das pessoas de agora até 2050 ? $^{9}$ Ambas vinham acompanhadas de 15 alternativas, desde invenções técnicas e inovações (19a), desenvolvimento da ciência e do conhecimento (19f), passando por guerras e conflitos (19g), até migrações (191) e cientistas e engenheiros (19o). As respostas nos cinco países apresentam, com alguns matizes, a mesma tendência, e os resultados não diferem, em grande medida, entre uma e outra questão.

\footnotetext{
${ }^{7}$ A Noite do Lápis refere-se ao sequestro de 10 estudantes secundaristas da cidade de La Plata, iniciado na noite de 16 de setembro de 1976, durante o governo militar de Jorge Rafael Videla. As vítimas eram, em sua maioria, vinculadas à União Estudantil Secundária. Os estudantes sequestrados, exceto uma, tinham se mobilizado no ano anterior para obterem passagem estudantil com tarifa preferencial, o que foi cancelado após o golpe de março de 1976. Durante o cativeiro, os jovens foram torturados, o que levou a maioria deles a óbito. O fato ficou conhecido quando um dos sobreviventes, Pablo Díaz, fez seu depoimento no Juízo às Juntas em 1985, e foi amplamente divulgado na imprensa, através de um livro e do filme La noche de los lapices, que estreou em 1986.

${ }^{8}$ Para o espanhol, a pergunta foi vertida da seguinte forma: ¿Qué influencia encontrás que tuvieron los siguientes factores en el cambio de la vida de las personas en la historia más reciente?

${ }^{9}$ Para o espanhol, a pergunta teve a seguinte configuração: 20. ¿Qué influencia pensás que tendrán los siguientes factores en el cambio de la vida de las personas en los próximos 40 años?
} 
Figura 3 - Que influência você acha que terão os seguintes fatores na mudança da vida das pessoas de agora até 2050? (médias)*

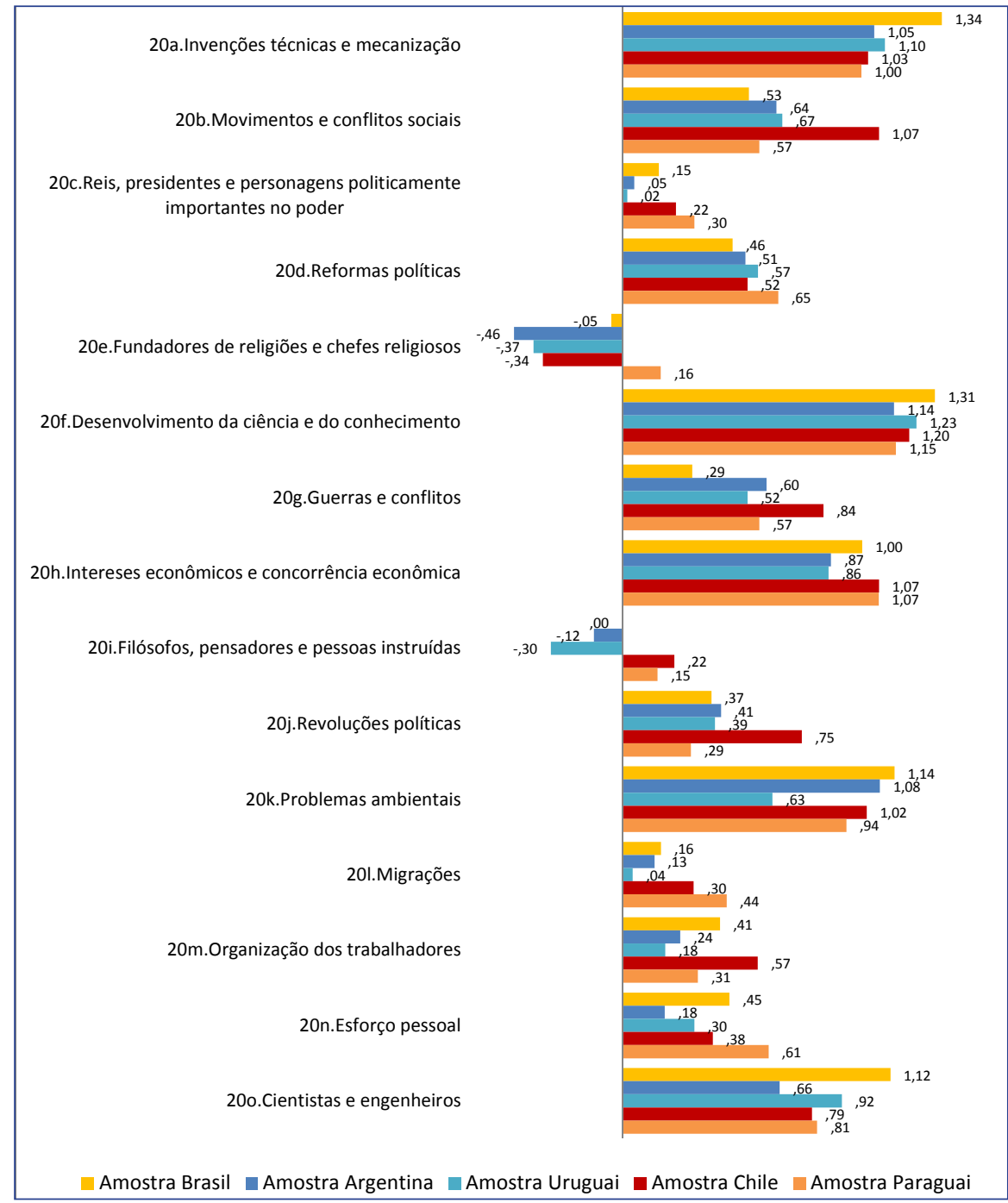

Fonte: Dados do projeto Jovens e a História. Questão no 38 (2013). Disponível em: <http://proyectozorzal.org>. Acesso em: 22 jul. 2017.

* As médias indicadas no gráfico foram compostas a partir da transformação das respostas, da escala Likert para uma escala numérica (muito pouca $=-2$; pouca $=-1$; média $=0$; grande $=1$; muito grande $=2$ ), sobre a qual se calculou a média aritmética das repostas em cada item.

As respostas informam que os estudantes privilegiam, de modo significativo, a contribuição da ciência e do conhecimento, bem como as inovações tecnológicas como as variáveis capazes de explicar o mundo 
atual. As opções sobre as invenções técnicas e a mecanização (20a), e o desenvolvimento da ciência e do conhecimento (20f) destacam-se em ambas as respostas. Contudo, no caso da questão $n^{0} 20$, pode-se afirmar que o resultado é mais incisivo, já que a alternativa de importância muito grande é mais selecionada do que na questão de $\mathrm{n}^{0} 19$.

As respostas indicam algumas hipóteses iniciais. Tal percepção poderia estar mais ancorada em ideias aprendidas fora da escola do que nela. Isto porque, muito embora nos últimos tempos, diferentes países tenham incorporado perspectivas mais variadas ao estudo do passado, ainda se observa certo centramento nos processos políticos e nos fatos históricos de um passado que não é recente. Deste modo, poderia ser lícito supor que a percepção da importância da ciência, da tecnologia e do conhecimento seja influenciada mais pelo que se aprende sobre mudanças e processos fora da sala de aula, por meio, principalmente, dos meios de comunicação de massa, do que na escola. Um aspecto que pode ser atribuído às mudanças no ensino de História, ainda que se considere, também, a influência extraescolar, é a importância relativamente alta atribuída aos movimentos e conflitos sociais (19b) para o presente. Os dados favorecem a hipótese de que a escola é apenas mais um fator - e não é o mais importante - nas representações do passado, que predominam nas percepções dos jovens.

Ao mesmo tempo, percebe-se a importância dada pelos jovens às questões tecnológicas nas transformações pelas quais passamos/passaremos. Constata-se, a partir das respostas a questão $\mathrm{n}^{\circ} 19$, a presença, também, das questões políticas e sociais nas transformações recentes. Os entrevistados consideraram como grande a influência, na História recente, a atuação dos presidentes e personagens politicamente importantes (19c), os movimentos e conflitos sociais (19b), as reformas políticas (19d), os interesses econômicos e competência econômica $(19 \mathrm{~h})$, bem como as questões referentes à organização dos trabalhadores $(19 \mathrm{~m})$ e as revoluções políticas (19j). Estes resultados se devem ao enfoque da História aprendida na escola? História que, apesar das mudanças nas últimas décadas, ainda mantém um grande espaço para as questões políticas e incorporou as discussões econômicas e os novos personagens, como os trabalhadores e os movimentos sociais sem, no entanto, deixar totalmente de lado uma História personalista. 
A novidade apresentada na questão de $\mathrm{n}^{0} 20 \mathrm{diz}$ respeito aos problemas ambientais, que passaram a ser considerados, pelos jovens, como um fator de impacto muito grande nas transformações nas próximas décadas, ficando lado a lado com os outros itens mais votados, que foram invenções técnicas e mecanização, e desenvolvimento da ciência e do conhecimento. Chama a atenção esta mudança, uma vez que, na questão $n^{\circ} 19$, que perguntava qual a influência dos mesmos fatores nas transformações ocorridas nas últimas décadas, o item problemas ambientais aparece como um fator de média e muito grande importância para a maioria dos respondentes da pesquisa, totalizando pouco mais de $30 \%$ das respostas em cada item.

A questão 26 seguiu investindo na busca de indícios sobre a percepção do tempo pelos jovens:

Figura 4 - Muitas vezes se olha a história como uma linha do tempo. Qual das seguintes linhas você pensa que descreve melhor o desenvolvimento da história? (em porcentagens)

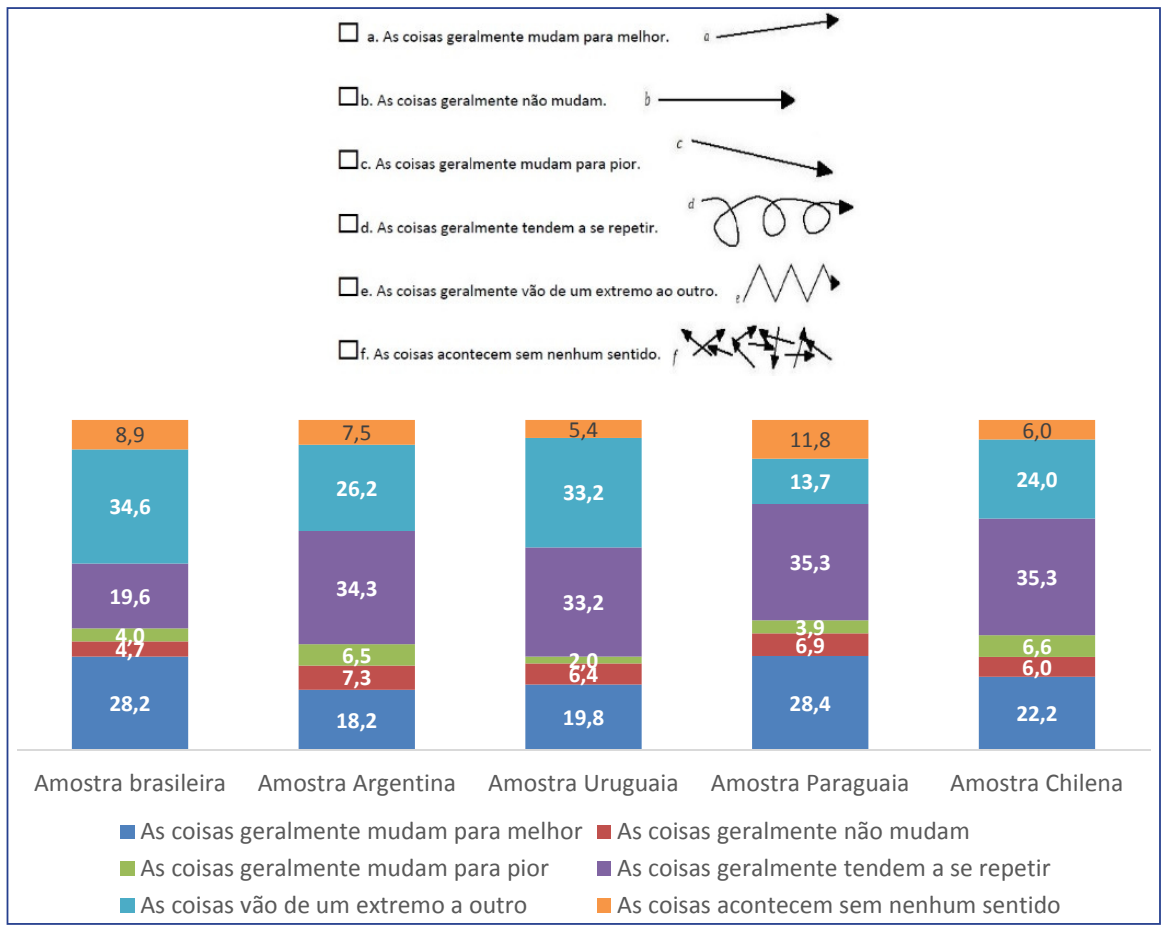

Fonte: Dados do projeto Jovens e a História. Questão № 26 (2013). Disponível em: <http://proyectozorzal.org>. Acesso em: 22 jul. 2017. 
A análise do total dos dados mostra que cerca de um quarto dos jovens consideram que as coisas mudam tendendo a melhorar no futuro, o que evidencia a longa duração da ideia de progresso, que ganhou força com o pensamento moderno e teve sua maior vigência entre 1750 e 1900. Essa visão otimista do futuro é mais forte entre os jovens do Paraguai e do Brasil, e mais fraca nos jovens da Argentina. Dentro das escolhas majoritárias encontra-se, também, as coisas geralmente tendem a se repetir, e no caso do Brasil, é uma alternativa que teve apenas 19,6\%, enquanto a média, nos demais países, foi em torno de $35 \%$. As alternativas foram minoritárias, mas as coisas geralmente não mudam parece mostrar uma visão fatalista, na qual ganhadores e perdedores da história estão predeterminados, e as coisas geralmente mudam para pior poderia ser considerada uma visão ainda mais negativa e extrema, que ressalta a incerteza do futuro. Nesta questão, chama a atenção a diferença entre o Brasil e os outros países, principalmente a Argentina, em relação às seguintes respostas: as coisas geralmente mudam para melhor e as coisas geralmente tendem a se repetir. Enquanto os jovens brasileiros podem ser considerados otimistas, uma vez que $28,2 \%$, contra $18,2 \%$ entre os argentinos, têm uma percepção de avanço e melhoria do presente em relação com o passado. No item as coisas geralmente tendem a se repetir ocorre o inverso: $34,3 \%$ dos argentinos versus $19,6 \%$ dos brasileiros. A ideia de repetição, o que pode remeter tanto a uma noção de tempo cíclico, como a noção de que a sociedade não aprende com suas experiências, é muito mais presente entre os jovens do país vizinho do que entre os jovens brasileiros. Este fator se complementa, no caso dos jovens brasileiros, ao identificarmos que $34,6 \%$ responderam que as coisas geralmente vão de um extremo a outro, o que remete a uma noção de instabilidade muito grande entre os nossos jovens. Nesta questão, o item $\mathrm{f}$, as coisas ocorrem sem nenhum sentido, não foi marcada pelos respondentes da pesquisa, o que denota que, para os jovens, as transformações temporais, seja de que modo se apresentam, possuem um sentido.

As questões 27, 28 e 29 buscaram respostas que confrontam perspectivas do passado e do futuro em relação ao presente dos jovens. A questão $\mathrm{n}^{\circ} 27$ quis saber: Como você pensa que era a vida do seu país há 40 anos? A 
de $\mathrm{n}^{\circ} 28$ - Como você acha que será a vida do seu país daqui a 40 anos? E a de $\mathrm{n}^{\circ} 29$ - Como você acha que será a sua vida daqui a 40 anos? As questões 27 e 28 repetem as 7 alternativas que vão desde Pacífica a Agitada por conflitos políticos, bem como as opções para cada uma delas que vão de muito difícil a muito provável. Esse conjunto de perguntas seguiu querendo conhecer as representações dos jovens sobre o passado recente e as perspectivas de futuro em relação aos seus países e a sua própria vida.

Figura 5 - Como você pensa que era a vida do seu país há 40 anos?

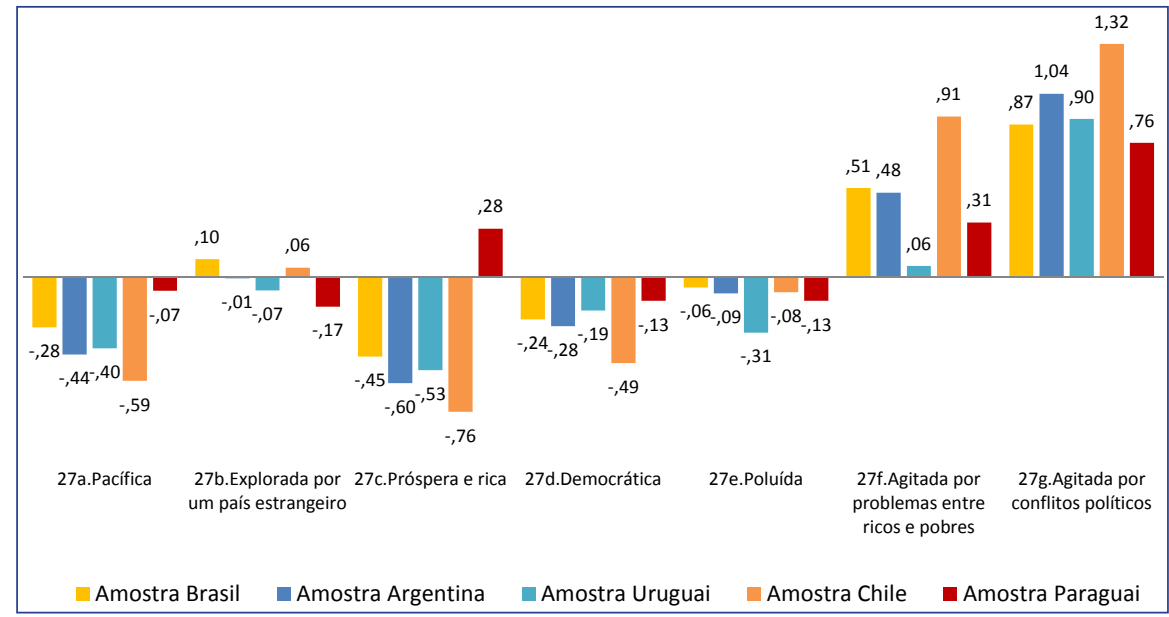

Fonte: Dados do projeto Jovens e a História. Questão no 27 (2013). Disponível em: <http://proyectozorzal.org>. Acesso em: 22 jul. 2017.

* As médias indicadas no gráfico foram compostas a partir da transformação das respostas, da escala Likert para uma escala numérica (muito dificilmente $=-2$; dificilmente $=-1$; talvez $=0$; provavelmente $=1$; muito provavelmente $=2$ ), sobre a qual se calculou a média aritmética das repostas em cada item.

Apesar da maior parte dos jovens ter assinalado o item talvez, o que remete provavelmente a uma insegurança e/ou desconhecimento sobre o passado do seu país em um período mais recente, podemos identificar a presença de algumas certezas: a constatação entre os jovens de que seus países não eram ricos e prósperos, bem como não eram pacíficos e/ou democráticos, que eram agitados por conflitos políticos e, em menor grau, pelas diferenças sociais. Com exceção da Argentina, conteúdos históricos mais recentes sobre a história nacional são pouco trabalhados nas aulas de História. No caso brasileiro é frequente, entre os professores de História, 
a constatação de que os conteúdos são muitos e que raramente conseguem trabalhar de modo mais aprofundado temas como a ditadura militar (19641985) e o processo de redemocratização.

Figura 6 - Como você acha que será a SUA vida daqui a 40 anos?

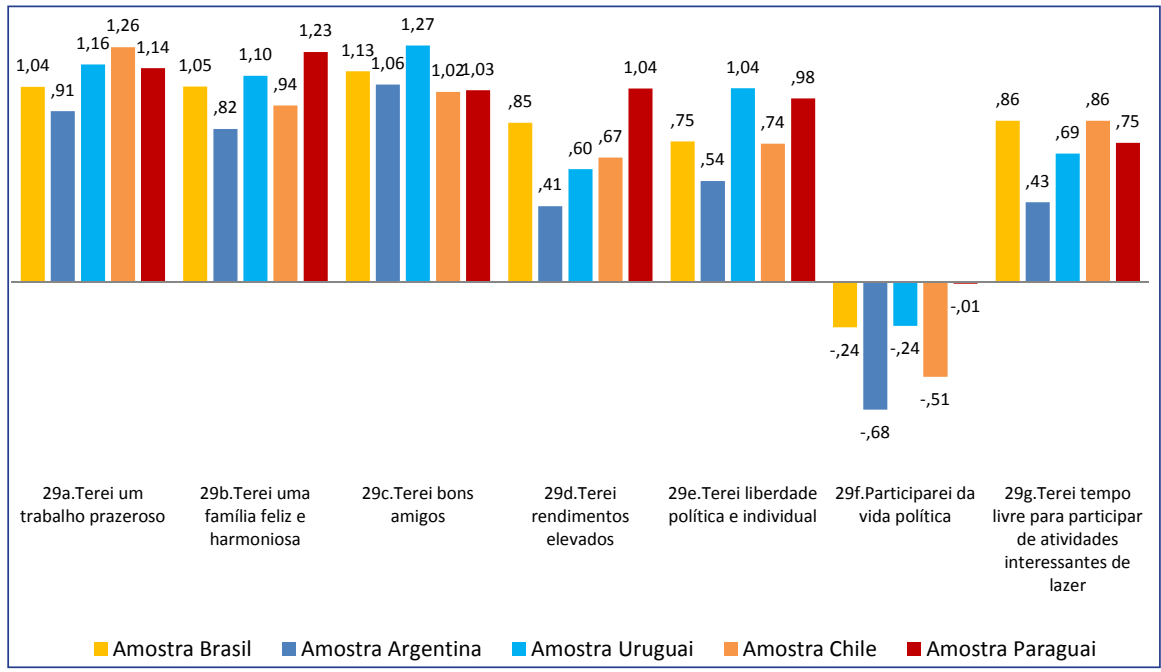

Fonte: Dados do projeto Jovens e a História. Questão № 29 (2013). Disponível em: <http://proyectozorzal.org>. Acesso em: 22 jul. 2017.

* As médias indicadas no gráfico foram compostas a partir da transformação das respostas, da escala Likert para uma escala numérica (muito dificilmente $=-2$; dificilmente $=-1$; talvez $=0$; provavelmente $=1$; muito provavelmente $=2$ ), sobre a qual se calculou a média aritmética das repostas em cada item.

Já na questão 29, ao falar do futuro, de como pensa que será sua vida nos próximos 40 anos, constata-se um grande otimismo em relação às conquistas pessoais, principalmente aquelas relacionadas às sociabilidades, como a construção de uma família e o estabelecimento de boas relações de amizade, e a confiança em relação à conquista de um trabalho que seja prazeroso e que lhe permita ganhos financeiros suficientes para poder gozar de tempo livre. A ênfase em um futuro que lhe permita ter prazer no trabalho, bem como ter tempo para o ócio, a recreação e as atividades interessantes é uma resposta (ou um desejo) em relação ao tempo presente, no qual os jovens, como estudantes, são obrigados a se dedicarem a atividades que não foram definidas por eles, e das quais muitos não gostam? Nas respostas a esta questão, identifica-se um grande otimismo, o que demonstra grande 
confiança dos jovens em si mesmos enquanto indivíduos, o que não se constata quando das respostas à questão 28 , quando é perguntado Como você acha que será a vida do seu país daqui a 40 anos? Nas respostas aos itens desta questão, identificou-se a continuidade do pessimismo em relação ao futuro coletivo. Esta contradição entre pessimismo em relação ao futuro do país e forte otimismo em relação a seu futuro pessoal talvez possa ser entendida a partir da percepção de um hiato entre o coletivo, o público e o individual, o privado. Para a maior parte dos jovens, a participação na vida política não é um horizonte de expectativa, ao mesmo tempo em que uma relativamente grande parte dos jovens respondeu talvez ao item 29e. Terá liberdade política e individual. Esta também é a conclusão a que chegam Miriam Abramovay, Mary Castro e Julio Waiselfisz na pesquisa Juventudes na Escola, Sentidos e Buscas: Por que frequentam? desenvolvida no ano de 2013 em 5 capitais e 5 municípios do interior nos estados do Rio de Janeiro, Bahia, Paraná, Mato Grosso e Pará com jovens entre 14 e 30 anos, na qual foram ouvidos jovens estudantes no Ensino Médio, EJA e Projovem Urbano ${ }^{10}$. A pesquisa foi desenvolvida a partir "de questões propostas pelos pesquisadores em questionários, possibilitando análise extensiva, parte do survey, como apreender práticas discursivas, [...] e em grupos focais e debates coletivos" (ABRAMOVAY; CASTRO; WAISELFISZ, 2015, p. 20). Uma das conclusões é de que as expectativas apresentadas pelos jovens, em relação a seu futuro, não fogem ao senso comum, e se restringem à inclusão nas regras do sistema, o que significa a busca por estudos que os habilitem ao acesso a um trabalho bem remunerado e a outros desejos, como constituir família e ser feliz. Segundo os pesquisadores, "os discursos sugerem uma juventude que, mesmo crítica da escola, e até das oportunidades sociais, não ousa relacionar seu futuro a outro futuro, o da sociedade" (ABRAMOVAY; CASTRO; WAISELFISZ, 2015, p. 235).

\section{CONSIDERAÇÕES FINAIS}

Esta pesquisa com os jovens possibilita algumas reflexões acerca da relação que eles estabelecem com o passado e com o futuro. Algumas das

\footnotetext{
${ }^{10}$ Entre os jovens entrevistados, $69,9 \%$ têm entre 15 e 19 anos de idade, 55,3\% são mulheres e 44,7\% são homens, e 63,5\% identificaram-se como pardos ou pretos.
} 
questões analisadas mostram que os jovens são vistos pela sociedade e por eles mesmos de modo dúbio. Apesar de os jovens terem uma representação negativa de si mesmos, se considerando como irresponsáveis e individualistas, eles também consideram que é sua função não somente se prepararem para o futuro, através da formação, mas também participarem das demandas do presente através da defesa de seus ideais. Ou seja, no presente, suas perspectivas dividem-se entre o individualismo e a preocupação com as demandas sociais. Sobre o papel do ensino de História, eles consideraramno importante para conhecer o passado, também muito importante para compreender o presente e orientar-se para o futuro. O que se constata é a permanência da noção de progresso, o que leva os jovens a uma postura positiva em relação ao futuro, principalmente ao seu futuro pessoal. No que se refere ao futuro coletivo, os jovens têm uma perspectiva distinta, alguns são marcadamente negativos, como os argentinos; outros bem mais otimistas, como os brasileiros e paraguaios.

Nas últimas décadas e cada vez mais, os jovens interpretam passado e futuro sob um presente alargado, hipertrofiado, o que impõe desafios ao ensino de História nas escolas por alterar de modo significativo a consciência temporal. O historiador franco-polonês Krzysztof Pomian (2013) analisa essa mudança, destacando que o futuro não é mais orientado pelo passado distante. Não que o passado não exista; ao contrário, é onipresente. Mas esse passado, para toda uma geração de jovens, acaba sendo depósito de eventos exóticos, estranhos. Ele é interessante e atrativo como conteúdo de filmes, novelas, romances, mas não como orientação temporal para um futuro coletivo. Assim, o ensino de História só seria relevante se o futuro fosse significado no presente, pois o passado distante não faria mais sentido para os jovens.

A orientação temporal centrada no presente é o mais difícil de superar como desafio, pois vai além do entendimento do tempo como histórico, cobrindo aspectos filosóficos e de constituição e significação da existência. Como tempo histórico, o presente se constrói em contraposição ao passado, e o passado é sempre reconstruído no presente. A diferença entre um e outro está no contraste, que é, também, uma operação mental, intelectual, 
emocional e, ao mesmo tempo, puramente arbitrária e subjetiva. Isto porque presente e passado são intervalos de tempo com comprimentos variáveis, ou seja, são durações que variam segundo escalas próprias e irredutivelmente plurais (POMIAN, 2013). Depreende-se que qualquer alteração na percepção de um desses tempos implica imediatamente a alteração da significação do outro.

\section{REFERÊNCIAS}

ABRAMO, Helena Wendel. Condição juvenil no Brasil contemporâneo. In: ABRAMO, Helena Wendel; BRANCO, Pedro Paulo Martoni (orgs.). Retratos da juventude brasileira. São Paulo: Editora Fundação Perseu Abramo, 2008, . p. 37-72.

ABRAMO, Helena Wendel. Considerações sobre a tematização social da juventude no Brasil. In: Juventude e contemporaneidade. Brasília: UNESC, MEC, ANPEd, 2007, p. 73-90.

ABRAMOVAY, Miriam; CASTRO, Mary; WAISELFISZ, Julio (org.). Juventudes na escola, sentidos e buscas: por que frequentam? BrasíliaDF: Flacso-Brasil, OEI, MEC, 2015. Disponível em: <http://flacso.org. $\mathrm{br}$ /?publication=juventudes-na-escola-sentidos-e-buscas-por-quefrequentam>. Acesso em: 25 set. 2016.

BERGMANN, Klaus. A História na reflexão didática. Dossiê História em Quadro-Negro: escola, ensino e aprendizagem. Revista Brasileira de História. São Paulo: vol. 9, n. 19, set. de 1989/fev. de 1990, p.30-32.

BOURDIEU, Pierre. A “Juventude” é apenas uma palavra. In: BOURDIEU, Pierre. Questões de sociologia. Rio de Janeiro: Marco Zero, 1983, p. 112-121. BRASIL. Estatuto da Criança e do Adolescente. Lei no 8.069, de 13 de julho de 1990. Disponível em: http://www.planalto.gov.br/ccivil_03/leis/18069. htm. Acesso: 26 jun. 2018.

. Lei $n^{\circ} 10.639$, de 9 de janeiro de 2003. Disponível em: http://www. planalto.gov.br/ccivil_03/Leis/2003/L10.639.htm. Acesso: 26 jun. 2018. 
. Lei $n^{\circ} 11.645$, de 10 de março de 2008. Disponível em: http:// www.planalto.gov.br/ccivil_03/_ato2007-2010/2008/lei/111645.htm. Acesso: 26 jun. 2018.

. Lei $n^{\circ} 12.061$, de 27 de outubro de 2009. Disponível em: http:// www.planalto.gov.br/ccivil_03/_ato2007-2010/2009/lei/112061.htm. Acesso: 26 jun. 2018.

Estatuto da Juventude. Lei no 12.852, de 5 de agosto de 2013. Disponível em: http://www.planalto.gov.br/ccivil_03/_ato2011-2014/2013/ lei/112852.htm. Acesso: 26 jun. 2018.

CERRI, Luis Fernando. Tipos de geração de sentido histórico - um ensaio com dados quantitativos. In: SCHMIDT, Maria A.; BARCA, Isabel.; URBAN, Ana C.. (Org.). Passados possíveis: a educação histórica em debate. Ijuí: Ed. Unijuí, 2014, p. 179-194.

DAYRELL, Juarez. O jovem como sujeito social. In: Juventude e contemporaneidade. Brasília: UNESC, MEC, ANPEd, 2007, p. 155-176.

KEHL, Maria Rita. A juventude como sintoma da cultura. In: NOVAES, Regina; VANNUCHI, Paulo (orgs.) Juventude e sociedade: trabalho, educação e participação. São Paulo: Editora Fundação Perseu Abramo, 2004, p. 89-114. LORENZ, Federico Guillermo. O passado recente na Argentina: as difíceis relações entre transmissão, educação e memória. In: CARRETERO, Mario; ROSA, Alberto; GONZÁLEZ, Maria Fernanda (orgs.) Ensino da história e memória coletiva. Porto Alegre: Artmed, 2007, p. 229-242.

MARGULIS, Mario; URRESTI, Marcelo. La juventud es más que una palabra. In: Margulis, M. (org.). La juventud es más que una palabra. Buenos Aires, Biblos, 1996, p. 19-32.

MINAYO, Maria Cecília. S; SANCHES, Odécio. Quantitativo-Qualitativo: Oposição ou Complementaridade? Cadernos de Saúde Pública, Rio de Janeiro, v. 9, n. 3, p. 239-262, jul/set. 1993. Disponível em: <http://unisc.br/ portal/upload/com_arquivo/quantitavivo_qualitativo_oposicao_ou_ complementariedade.pdf $>$. Acesso em: 17 set. 2016. 
MIRANDA, Sonia Regina; LUCA, Tânia Regina de. O livro didático de história hoje: um panorama a partir do PNLD. Revista Brasileira de História. São Paulo, v. 24, n 48, 2004, p. 123-144.

PERALVA, Angelina T.. O jovem como modelo cultural. In: Juventude e contemporaneidade. Brasília: UNESC, MEC, ANPEd, 2007, p. 13- 27.

POMIAN, Krzysztof. Partir du Présent. Le Débat, Éditions Gallimard, n 175 p.79-92, mai/out. 2013. Disponível em: <http://www.le-debat. gallimard.fr/articles/2013-3-partir-du-present>. Acesso em: 14 agost. 2014. PROYECTO ZORZAL, [s.d.]. Disponível em: 〈http://proyectozorzal.org〉. Acesso em: 22 jul. 2016.

RICOEUR, Paul. A memória, a história, o esquecimento. Campinas/SP: Unicamp, 2007.

RÜSEN, Jörn. História viva. Teoria da História: formas e funções do conhecimento histórico. Tradução de Estevão de Rezende Martins. Brasília: UNB, 2007.

RÜSEN, Jörn. Como dar sentido ao passado: questões relevantes de meta-história. História da Historiografia, n.2, p. 163-209, março 2009. Disponível em: <https:/www.historiadahistoriografia.com.br/revista/ article/view/12/12>. Acesso: 20 set. 2016.

RÜSEN, Jörn. Cultura faz sentido. Orientações entre o ontem e o amanhã. Tradução de Nélio Schneider. Petrópolis/RJ: Vozes, 2014.

SAVAGE, Jon. A criação da juventude: como o conceito de teenage revolucionou o século XX. Rio de Janeiro: Rocco, 2009. 